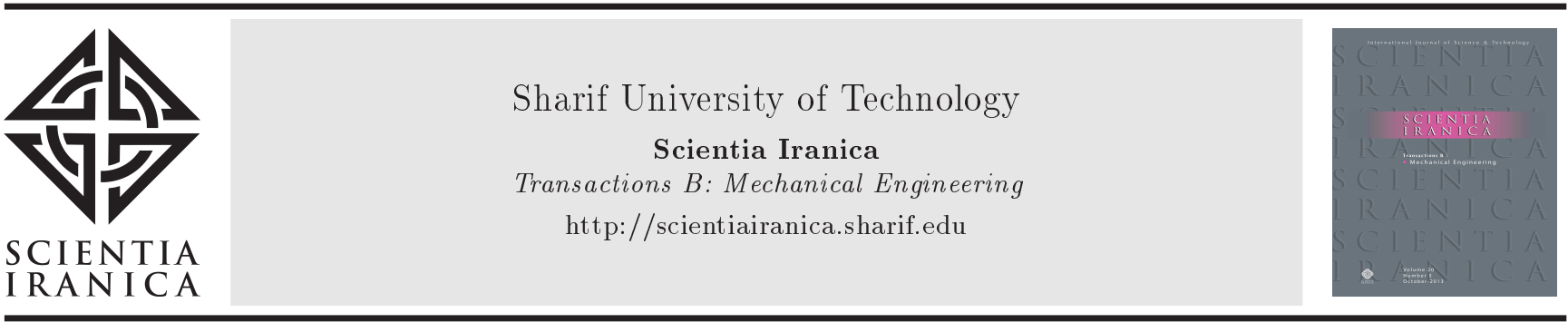

\title{
Machinability of hardened AISI S1 cold work tool steel using cubic boron nitride
}

\author{
A. Şahinoğlua,* and M. Rafighi ${ }^{\mathrm{b}}$ \\ a. Department of Mechanical and Metal Technology, Manisa Celal Bayar University, Manisa, Turkey. \\ b. Department of Mechanical Engineering, University of Turkish Aeronautical Association, Ankara, Turkey. \\ Received 25 May 2020; received in revised form 26 December 2020; accepted 6 July 2021
}

\author{
KEYWORDS \\ AISI S1 steel; \\ Hard turning; \\ Surface roughness; \\ Machining sound; \\ Power consumption; \\ Response surface \\ methodology.
}

\begin{abstract}
Recently, hard turning has become an interesting method for manufacturers as an alternative to the grinding process due to its superior features such as good surface quality, good productivity, lower production costs, lower power consumption, and shorter processing time. Despite its considerable benefits, hard turning is a difficult process that needs advanced cutting inserts such as ceramics and cubic boron nitride. However, these cutting inserts are costly and should be used properly by choosing appropriate machining parameters. In the presented work, the hard turning process was employed to investigate the machinability of AISI S1 cold work tool steel using a cubic boron nitride insert. The relation between machining parameters, namely depth of cut, cutting speed, and feed rate, on the responses such as power consumption, surface roughness, and machining sound was found using a full factorial orthogonal array of response surface methodology. In addition, analysis of variance was used to identify the most important machining parameters that influence output parameters. Based on the results, surface roughness was dominantly affected by feed rate, whereas sound and power consumption were influenced by all machining parameters, especially cutting speed and feed rate. Good agreement between the experimental and predicted values was observed.
\end{abstract}

(C) 2021 Sharif University of Technology. All rights reserved.

\section{Introduction}

In the last decades, hard turning is used as an alternative method to the grinding operation due to its superior properties such as shorter machining time, good surface finish, machining without coolant, lower manufacturing power, and cost. Further, hard turning allows good flexibility in the manufacturing of intricate geometries with good surface quality and dimensional accuracy [1-3]. Smaller feed rate and cutting depth are

\footnotetext{
*. Corresponding author. Tel.: +905413369826

E-mail addresses: abidin.sahinoglu@cbu.edu.tr, abidinsahinoglu@gmail.com (A. Şahinoğlu); mrafighi@thk.edu.tr, mohammad.rafighi@gmail.com (M. Rafighi)
}

required to remove much more material in hard turning than grinding; hence, a good material removal rate is one of the notable characteristics of hard turning [4,5]. Hard turning is performed on various materials with hardness larger than 45 Rockwell using single-point cutting tools such as ceramics and Cubic Boron Nitride $(\mathrm{CBN})$ due to their remarkable properties, namely high strength, high wear resistance, and high hardness [6$9]$. These cutting inserts produce good surface quality and smaller flank wear during the turning of hardened steel [10]. Many studies have been done related to the effect of cutting parameters and workpiece materials on the power consumption $[11,12]$, tool wear $[13,14]$, cutting forces $[15,16]$, and surface roughness $[17,18]$ during hard turning.

The cold work tool steels such as AISI S1 [19] and AISI D3 [20] contain a high amount of carbon. 
Besides, they have a low amount of molybdenum, silicon, chromium, manganese, vanadium, and tungsten in their chemical composition. The carbon element of cold work tool steel increases the wear resistance of the workpiece, while other elements increase the toughness and hardenability $[21,22]$. The AISI S1 cold work tool steel material is used in many applications as cutting tools for cold cutting, cold shear blades, blanking dies, cold piercing punches, woodworking tools, scrapping scissors, industrial knives, shear blades, and ejectors.

Machinability can be defined as the ease of the metal removal process using proper cutting tools and machining parameters. Many criteria affect machinability; however, power consumption [11], tool wear [13], cutting forces [16], surface quality [18], and tool life [23] are the most important ones [24]. Surface finish is used to evaluate the machined surface quality and productivity of machine tools. Therefore, it is of great importance to investigate the surface quality of the machined workpiece in order to express machining performance.

Chou et al. [25] studied tool flank wear and surface finish during hard turning of 62 Rockwell AISI 52100 steel using various CBN cutting tools. Scanning Electron Microscopy (SEM) was used to characterize the wear behavior of $\mathrm{CBN}$ inserts. According to the results, the low cubic boron nitride content tools (CBNL) exhibited better performance than high content CBN tools. The flank wear has a direct proportion with cutting speed and increasing the cutting speed increases the flank wear. In most studies, the surface roughness is mainly affected by the feed rate. However, in this study, the feed rate was kept constant, the depth of cut was effective, and the low depth of cut produced a good surface in low content CBN.

Devim and Figueira evaluated the effect of input parameters on surface quality during hard turning of AISI D2 tool steel having a hardness of 60 Rockwell using ceramic cutting tools. Analysis Of Variance (ANOVA) was utilized to detect the most important parameters that influence surface quality. The results indicated that the tool wear was greatly affected by cutting speed by $57 \%$ contribution. As the cutting speed increased, the tool wear also increased. Also, the feed rate was found as a dominant factor influencing surface roughness [26].

In another experimental study by Isik [27], the machinability of various cold work tool steels such as AISI H10, AISI O2, and AISI 420 was evaluated. The workpiece materials, cutting parameters, and cutting tools coating were considered as input parameters, while the surface roughness, tool flank wear, and cutting forces were considered as responses. The results indicated that tool life was mainly influenced by cutting speed and feed rate, whereas the tool nose radius was a significant factor in the surface roughness.
Bouacha et al. [28] presented an experimental study related to the hard turning of AISI 52100 bearing steel (64 Rockwell) using CBN cutting tools. The depth of cut, feed rate, and cutting speed were selected as cutting parameters, the tool wear, cutting forces, and surface roughness were chosen as response parameters. The most effective cutting parameters affecting output parameters were found using the ANOVA. The relation between machining parameters and the responses such as surface roughness and cutting forces was chosen using Response Surface Methodology (RSM). According to the results, the feed rate and cutting speed were the most important factors that would affect surface quality. In addition, the cutting forces were mainly influenced by workpiece hardness, negative rake angle, and tool wear, respectively.

Lima et al. [29] investigated the machinability of hardened AISI D2 cold work tool steel (58 HRC) and hardened AISI 4340 high-strength low alloy steel (42 and $50 \mathrm{HRC}$ ) using mixed alumina, Polycrystalline Cubic Boron Nitride (PCBN), and coated carbide cutting inserts, respectively. In this experimental study, input parameters include feed rate, depth of cut, and cutting speed, while output parameters were surface roughness, tool wear, cutting forces, and tool life. Based on the results of this study, good surface quality was obtained during the turning of hardened AISI D2 tool steel employing a low feed rate and high cutting speed. However, increasing the cutting speed causes tool flank wear in mixed alumina inserts. Besides, during the turning of hardened AISI 4340 high strength low alloy steel (50 HRC), the cutting forces were reduced by increasing the cutting speed due to increase in the temperature in the shear zone that facilitated the material removal process. Finally, the main reason for flank wear during the hard turning of 42 HRC steel was abrasion.

Gaitonde et al. [30] stated that hard turning with ceramic tools provided many advantages over the grinding process such as decreasing manufacturing cost, improving surface quality, reducing power consumption, and enhancing productivity. Therefore, they investigated the turning of hardened high chromium AISI D2 cold work tools using various ceramic cutting tools such as GC6050WH, CC650WG, and CC650. They considered machining time and depth of cut as input parameters and tool wear, surface roughness, cutting force, and power consumption as responses. The results indicated that the CC650WG wiper insert produced good surface quality and low tool wear. However, the cutting forces and power consumption were reduced using CC650 conventional inserts.

Bensouilah et al. [31] presented an experimental study to explore the effects of input parameters such as cutting speed, depth of cut, and feed rate on the cutting forces and surface roughness during turning of 
hardened AISI D3 tool steel by employing CC6050 and CC650 ceramic inserts. The Taguchi method, ANOVA, RSM, and linear regression model were employed to evaluate the machinability of the workpiece material. The results showed that the CC6050 ceramic insert exhibited better surface quality than uncoated CC650 ceramic inserts by 1.6 times. The feed rate was the dominant factor that affected surface roughness followed by cutting speed. Moreover, the cutting forces were greatly affected by the depth of cut. The uncoated ceramic insert exhibited good performance in decreasing the cutting forces.

Aouici et al. [32] presented the impacts of depth of cut, feed rate, and cutting speed on the cutting forces, power consumption, and surface roughness during turning of hardened AISI D3 cold work tool steel (60 HRC) employing ceramic cutting inserts. The RSM was used to obtain optimum cutting parameters and the ANOVA was employed to determine the most significant parameter. The results showed that the feed rate was the most important factor that would affect the surface quality and power. In order to determine the best surface quality, minimum power consumption, and cutting forces, the workpiece should be machined with a low depth of cut, high cutting speed, and low feed rate.

Şahinoğlu and Rafighi [33] investigated the effects of cutting parameters on surface roughness, vibration, sound intensity, and current values during turning of AISI 4140 steel using coated carbide cutting inserts. They employed RSM and ANOVA to determine the relationship between machining parameters-response variables and the significant factors that affect the outputs, respectively. The results revealed that surface roughness was mainly influenced by the feed rate. The other responses namely current, sound intensity, and vibration were affected by both feed rate and depth of cut. As the aforementioned machining parameters increase in value, the responses also increase. Finally, good agreement was obtained between experimental and predicted data.

In another study by Şahinoğlu and Rafighi [34], the effect of machining parameters and workpiece hardness was investigated during turning of AISI 1040 steels. According to the results, the feed rate is the most significant factor in power consumption and surface roughness.

In the last four decades, many experimental studies have been conducted to investigate the machinability of hardened steels using different cutting inserts such as CBN, coated carbide, and ceramic. However, the number of studies that has focused on the machinability of the hardened cold work tool steels considering sound and power consumption is limited. The goal of this study is to explore the effects of machining parameters such as feed rate, depth of cut, and cutting speed on the machinability factors, namely power consumption, surface roughness, and sound during turning of hardened AISI S1 cold work tool steel employing CBN cutting inserts. This study is performed by applying the RSM to determine the relationship between input and output parameters. In addition, ANOVA was used to determine the most important factor that would affect the response parameters and multiple linear regression equations were established to determine the response variables numerically using the correlation between input and output parameters.

\section{Materials and methods}

\subsection{AISI S1 properties and applications}

In the presented work, hard turning was performed on AISI S1 cold work tool steel utilizing CBN inserts to explore the effects of input parameters such as depth of cut, cutting speed, and feed rate on output parameters such as sound, power consumption, and surface roughness. The notable properties of AISI S1 steel are good toughness, good shock resistance, and good hardenability. This material is appropriate for cold work tools subjected to high shock. The AISI S1 steel can be used for cutting tools, shear knives, and ejector pins. The designation related to this material for DIN standard is 1.2550 , for EN standard is $60 \mathrm{WCrV} 8$, and for AISI/ASTM standard is S1.

\subsection{Workpiece material}

In this study, AISI S1 cold work tool steel bar was used as a workpiece material with a $50 \mathrm{~mm}$ diameter and a $200 \mathrm{~mm}$ length. The length-to-diameter ratio for this cylindrical workpiece was kept as 4 to maintain the stiffness of the workpiece, chuck, and cutting tool. The heat treatment was performed at $860^{\circ} \mathrm{C}$ for two hours; then, it was quenched in the oil for 30 minutes and finally, was tempered for 1 hour at $200^{\circ} \mathrm{C}$ to remove residual stresses and obtain $60 \mathrm{HRC}$ hardness. The machining time for each pass was almost one minute and the measuring period for surface roughness was almost two minutes. The chemical composition of AISI S1 cold work tool steel is presented in Table 1.

\subsection{Cutting conditions}

Generally, the turning process on the lathe is applied using three main parameters, namely cutting speed

Table 1. Chemical composition of AISI S1 cold work tool.

\begin{tabular}{cccccccc}
\hline $\mathrm{Si}(\%)$ & $\mathrm{C}(\%)$ & $\mathrm{P}(\%)$ & $\mathrm{Mn}(\%)$ & $\mathrm{Cr}(\%)$ & $\mathrm{S}(\%)$ & $\mathrm{W}(\%)$ & $\mathrm{V}(\%)$ \\
\hline $0.55-0.70$ & $0.55-0.65$ & 0.30 & $0.15-0.45$ & $0.90-1.20$ & 0.30 & $1.70-2.20$ & $0.10-0.20$ \\
\hline
\end{tabular}


Table 2. The cutting parameters.

\begin{tabular}{lcccc}
\hline & & \multicolumn{3}{c}{ Levels } \\
\cline { 3 - 5 } Cutting parameters & Units & $\mathbf{1}$ & $\mathbf{2}$ & $\mathbf{3}$ \\
\hline Feed rate $(f)$ & $\mathrm{mm} / \mathrm{rev}$ & 0.05 & 0.10 & 0.15 \\
Cutting speed $(V)$ & $\mathrm{m} / \mathrm{min}$ & 180 & 200 & 220 \\
Depth of cut $(a)$ & $\mathrm{mm}$ & 0.10 & 0.15 & 0.20 \\
\hline
\end{tabular}

$(V)$, feed rate $(f)$, and depth of cut $(a)$. Determining the optimum machining parameters with emphasis on output parameters is very important in order to reduce the cost of manufacturing. The machining parameters are chosen based on previous studies and the manufacturer's handbook (considering the workpiece material and cutting insert). In the presented work, the hard turning was performed on AISI S1 tool steel using CBN cutting inserts. The cutting parameters for the presented work are shown in Table 2.

The turning tests were carried out on the TAKSAN TTC-630 model Computerized Numerical Control (CNC) lathe having a maximum power of $20 \mathrm{~kW}$ and a maximum speed of $4000 \mathrm{rpm}$ under dry cutting conditions.

\subsection{Cutting inserts}

In this experimental study, CBN inserts manufactured by the Sandvik company with DCGW11T304S01020FWH 7015 ISO designation were used due to their high thermal and abrasion resistance. The recommended cutting parameters for this insert according to the manufacturer's catalog include cutting speed $(160-250 \mathrm{~m} / \mathrm{min})$, feed rate (0.05-0.25 mm/rev), and depth of cut $(0.05-0.40 \mathrm{~mm})$. The Physical Vapor Deposition (PVD) is applied to coat carbide inserts with TiN layer. It has a 3.969 $\mathrm{mm}$ thickness, $0.40 \mathrm{~mm}$ tool nose radius, negative $55^{\circ}$ cutting tip, and $9.525 \mathrm{~mm}$ inscribed diameter. Furthermore, the MWLNR 2525 M08 tool holder was used to mount the cutting inserts. CBN insert is shown in Figure 1.

\subsection{Measuring devices}

First, the instantaneous current and sound values were measured during the turning operation. Then, surface roughness value was measured after each turning process. The Lutron SL-401 device was employed to measure the sound of the process during the turning operation. There are instantaneous fluctuations in the sound during a turning process that affect the sound measuring process negatively. In order to avoid these fluctuations, Lutron SL-401 portable device was located at a distance of $900 \mathrm{~mm}$ from the CNC lathe.

The UNI-T UT201 device was used to measure the machine current. The total current value was calculated by multiplying the current value of one phase by three. Therefore, the total power consumption of the CNC lathe machine for each turning process was obtained by multiplying the voltage $(380 \mathrm{~V})$ by the total current value. The Lutron SL-401 and UNI-T UT201 devices are shown in Figure 2(a) and (b), respectively.

Surface roughness ( $\mathrm{Ra}$ ) was measured using an Mitutoyo SJ 201 portable device. The surface roughness value for each turning test was measured considering the mean value of three measurements from three different locations of the outer diameter of the workpiece. The measuring process on the machined surface is shown in Figure 3. The experimental setup is given in Figure 4 .

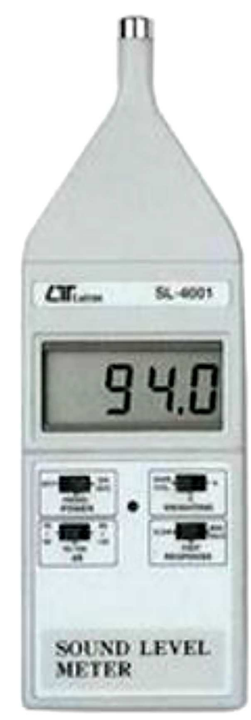

(a)

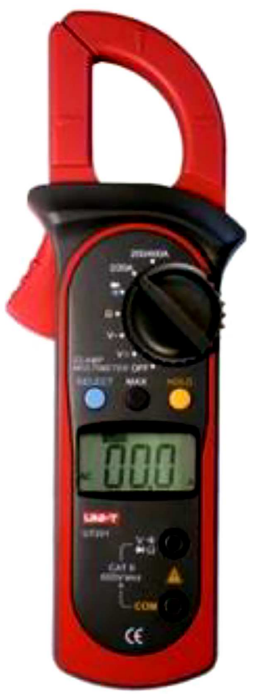

(b)
Figure 2. (a) Sound measuring device. (b) Current measuring device.
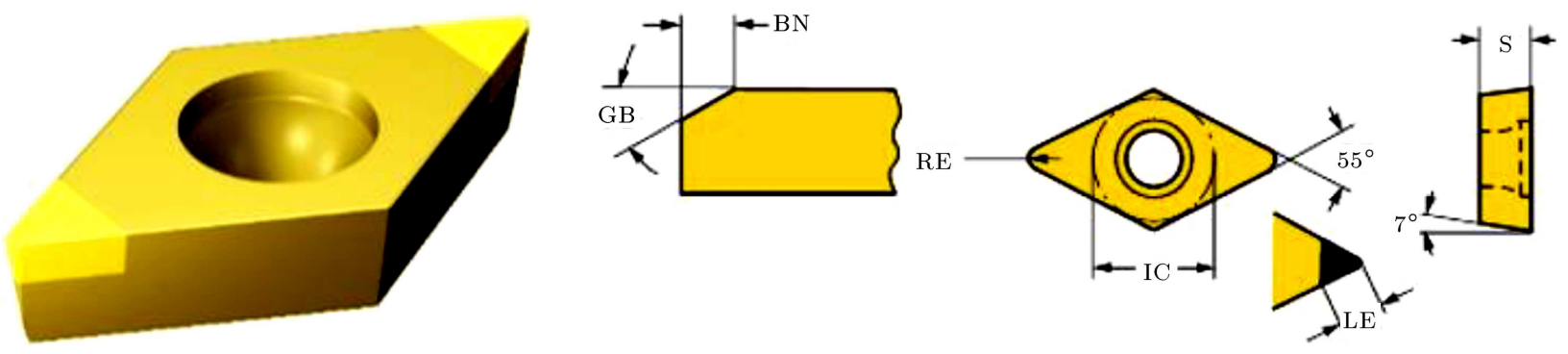

Figure 1. The Sandvik DCGW11T304S01020FWH 7015 cubic boron nitride insert. 


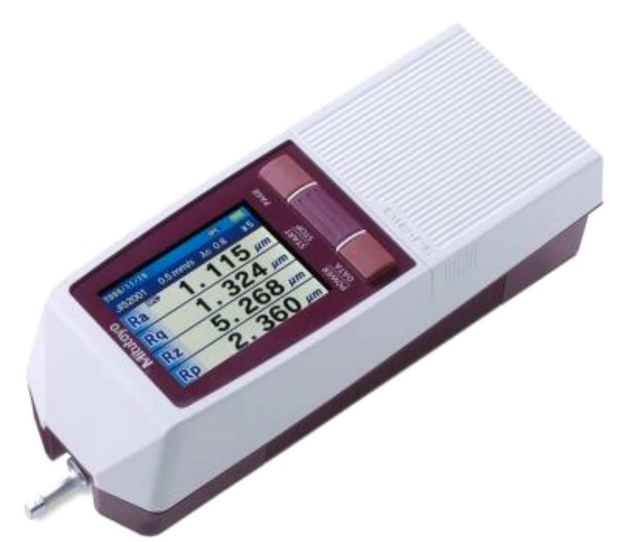

Figure 3. A surface roughness measuring device.
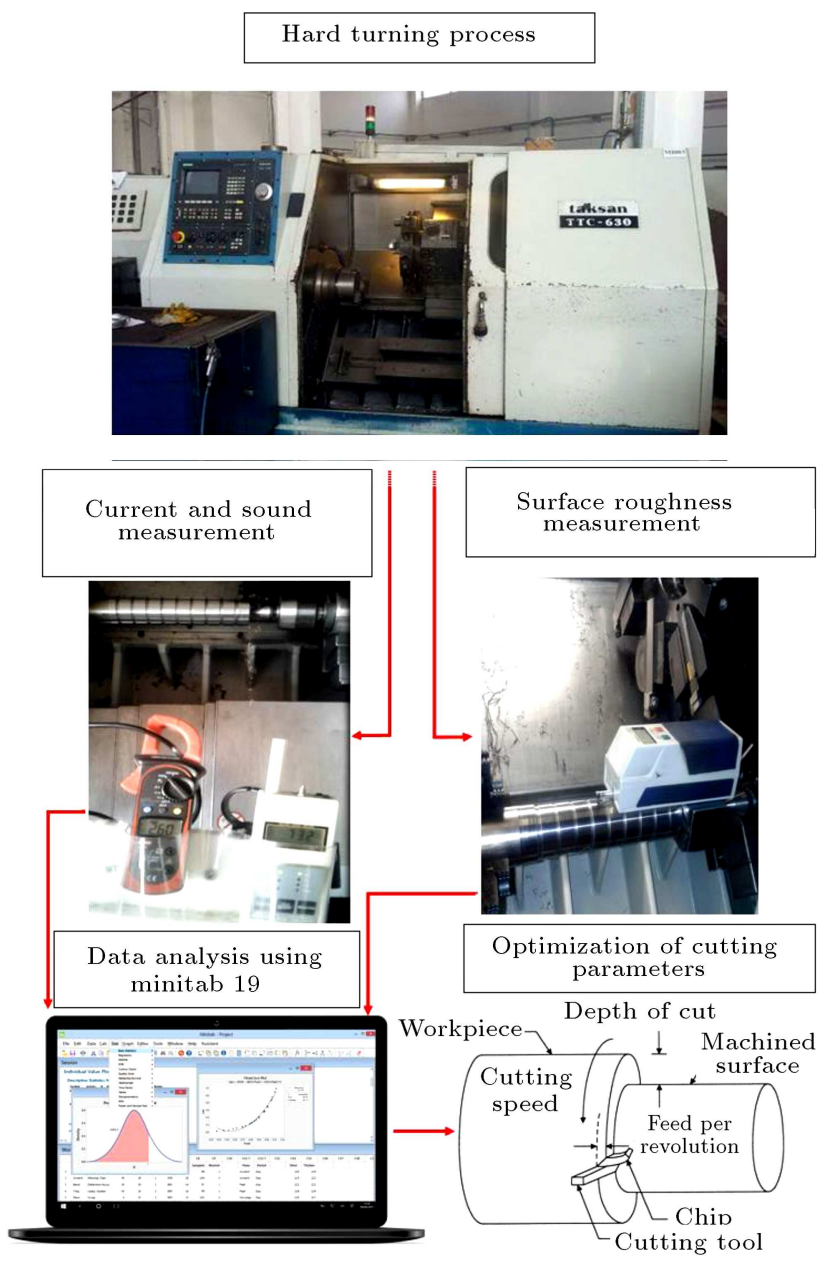

Figure 4. Experimental setup for hard turning of AISI S1 steel.

\subsection{Response Surface Methodology (RSM)}

This method is used to determine the relationship between cutting parameters and response variables. In addition, the RSM is a good method to develop, improve, and optimize the processes besides identifying the significant input factors on responses within the design layout. The formula between independent input factors and desired response is given in Eq. (1):

$$
Y=\emptyset(a, V, f),
$$

where $Y$ is the desired output parameter and $\phi$ is the output parameter function. In this experimental study, the following steps are carried out:

1. Defining the cutting parameters and response variables;

2. Adopting a full factorial orthogonal array experimental design layout;

3. Developing the regression equations and calculating the coefficient of determination $\left(R^{2}\right)$ based on RSM;

4. Performing the ANOVA for cutting parameters to identify the dominant parameter that influences the responses;

5. Obtaining the interaction plots, surface plots, residual graphs, normal plots, and Pareto charts of the standardized effects;

6. Validating the mathematical model by performing the confirmation test;

7. Analyzing the results of the RSM.

\section{Results and discussion}

In this study, the impacts of machining parameters such as cutting speed, depth of cut, and feed rate on the machinability of hardened AISI S1 tool steel were investigated using $\mathrm{CBN}$ inserts under dry cutting conditions. The results of the presented work were analyzed using ANOVA, RSM, and regression equations. Minitab 19 software was employed to analyze the obtained data. The results were divided into five parts. First, the results of the ANOVA for response variables were investigated to identify the most important factor. Second, the interaction plots, the normal plots, and Pareto charts for input and output parameters were presented. Third, the surface plot for the effect of the combination of input parameters on outputs was provided. Fourth, the regression equations were provided and the coefficients of determination were presented. Finally, the confirmation test was carried out to check the reliability of the proposed mathematical models.

\subsection{Experimental results}

In this study, the $L_{27}$ full factorial orthogonal array was chosen that contains $\left(3^{3}=27\right)$ trials regarding the combination of three cutting speeds, three depths of cut, and three feed rates. The first three columns were assigned to the machining parameters including cutting speed $(V)$, depth of cut $(a)$, and the feed rate $(f)$. The next three columns were assigned to the response parameters: power consumption $(P W)$, surface roughness $(R a)$, and sound $(S)$. The design of the experiment and the results of the responses are given in Table 3 . 
Table 3. The experimental results based on a full factorial orthogonal array.

\begin{tabular}{|c|c|c|c|c|c|c|}
\hline \multirow[b]{2}{*}{ Trial no. } & \multicolumn{3}{|c|}{ Input parameters } & \multicolumn{3}{|c|}{ Output parameters } \\
\hline & $a(\mathrm{~mm})$ & $V(\mathrm{~m} / \mathrm{min})$ & $f(\mathrm{~mm} / \mathrm{rev})$ & $R a(\mu \mathrm{m})$ & $P W$ (Watt) & $S(\mathrm{~dB})$ \\
\hline 1 & 0.1 & 180 & 0.05 & 0.29 & 2861.4 & 73.4 \\
\hline 2 & 0.1 & 180 & 0.10 & 0.86 & 2975.4 & 73.6 \\
\hline 3 & 0.1 & 180 & 0.15 & 1.26 & 3032.4 & 73.7 \\
\hline 4 & 0.1 & 200 & 0.05 & 0.22 & 2964.0 & 73.5 \\
\hline 5 & 0.1 & 200 & 0.10 & 0.76 & 3043.8 & 73.8 \\
\hline 6 & 0.1 & 200 & 0.15 & 1.33 & 3123.6 & 74.0 \\
\hline 7 & 0.1 & 220 & 0.05 & 0.25 & 3055.2 & 74.8 \\
\hline 8 & 0.1 & 220 & 0.10 & 0.72 & 3169.2 & 75.0 \\
\hline 9 & 0.1 & 220 & 0.15 & 1.42 & 3271.8 & 75.2 \\
\hline 10 & 0.15 & 180 & 0.05 & 0.28 & 2986.8 & 73.1 \\
\hline 11 & 0.15 & 180 & 0.10 & 0.67 & 3078.0 & 73.2 \\
\hline 12 & 0.15 & 180 & 0.15 & 1.20 & 3157.8 & 73.3 \\
\hline 13 & 0.15 & 200 & 0.05 & 0.30 & 3032.4 & 73.1 \\
\hline 14 & 0.15 & 200 & 0.10 & 0.72 & 3169.2 & 73.0 \\
\hline 15 & 0.15 & 200 & 0.15 & 1.35 & 3283.2 & 73.2 \\
\hline 16 & 0.15 & 220 & 0.05 & 0.29 & 3123.6 & 73.3 \\
\hline 17 & 0.15 & 220 & 0.10 & 0.57 & 3294.6 & 73.6 \\
\hline 18 & 0.15 & 220 & 0.15 & 1.23 & 3431.4 & 74.3 \\
\hline 19 & 0.2 & 180 & 0.05 & 0.39 & 2998.2 & 73.2 \\
\hline 20 & 0.2 & 180 & 0.10 & 0.51 & 3135.0 & 73.3 \\
\hline 21 & 0.2 & 180 & 0.15 & 1.14 & 3249.0 & 73.5 \\
\hline 22 & 0.2 & 200 & 0.05 & 0.31 & 3032.4 & 73.3 \\
\hline 23 & 0.2 & 200 & 0.10 & 0.52 & 3203.4 & 73.4 \\
\hline 24 & 0.2 & 200 & 0.15 & 1.16 & 3374.4 & 73.7 \\
\hline 25 & 0.2 & 220 & 0.05 & 0.39 & 3146.4 & 74.1 \\
\hline 26 & 0.2 & 220 & 0.10 & 0.45 & 3340.2 & 74.2 \\
\hline 27 & 0.2 & 220 & 0.15 & 1.14 & 3545.4 & 74.5 \\
\hline
\end{tabular}

\subsection{Surface roughness (Ra)}

The ANOVA results for surface roughness are presented in Table 4. In this table, $F$ is the variance ratio, $P$ the significant factor, and DF the degree of freedom. The significance level of $\alpha=0.05$ was chosen to perform this analysis. In other words, the machining parameter is statistically significant, while the $P$-value is smaller than 0.05 .

The ANOVA result indicates that the feed rate is the most influential parameter that affects surface roughness by $91.77 \%$ contribution. The same results were obtained in studies [26-29] that indicated the effect of feed rate on surface roughness. The reason for this phenomenon is the direct relation between feed rate and surface roughness based on Eq. (2):

$$
R a=\frac{f^{2}}{32 r},
$$

where $R a$ is the arithmetic surface roughness, $f$ the feed rate, and $r$ the tool nose radius. Another reason for poor surface quality is enhancing the cutting force as a result of a high feed rate. Therefore, the high cutting forces generate heat that deteriorates the surface quality. Also, the square of feed rate $\left(f^{2}\right)$ and the interaction of depth of cut-feed $\left(a^{*} f\right)$ rate have a minor impact on surface quality by $2.41 \%$ and $1.54 \%$ contributions, respectively. Based on the results, the cutting speed has no significant impact on surface quality in contrast with studies in $[28,29]$.

The Pareto chart and the normal plot of standardized effects for surface roughness are presented in Figures 5 and 6 , respectively. The Pareto chart shows that the feed rate is the dominant factor that imprints surface quality. Other parameters such as $\left(f^{2}\right),\left(a^{*} f\right)$, and $(a)$ have minimum influence on the surface. In the normal plot for $\alpha=0.05$, those significant parameters 
Table 4. The ANOVA results for surface roughness.

\begin{tabular}{|c|c|c|c|c|c|c|c|c|}
\hline Source & DF & Seq SS & Adj SS & Adj MS & $F$-value & $P$-value & Contribution & Remarks \\
\hline Model & 9 & 4.27073 & 4.27073 & 0.47453 & 71.10 & 0.000 & $97.41 \%$ & \\
\hline Linear & 3 & 4.09165 & 4.09165 & 1.36388 & 204.37 & 0.000 & $93.33 \%$ & \\
\hline$a$ & 1 & 0.06722 & 0.06722 & 0.06722 & 10.07 & 0.006 & $1.53 \%$ & Not significant \\
\hline$V$ & 1 & 0.00109 & 0.00109 & 0.00109 & 0.16 & 0.691 & $0.02 \%$ & Not significant \\
\hline f & 1 & 4.02334 & 4.02334 & 4.02334 & 602.87 & 0.000 & $91.77 \%$ & Significant \\
\hline Square & 3 & 0.10742 & 0.10742 & 0.03581 & 5.37 & 0.009 & $2.45 \%$ & \\
\hline$a^{2}$ & 1 & 0.00019 & 0.00019 & 0.00019 & 0.03 & 0.870 & $0.00 \%$ & Not significant \\
\hline$V^{2}$ & 1 & 0.00145 & 0.00145 & 0.00145 & 0.22 & 0.647 & $0.03 \%$ & Not significant \\
\hline$f^{2}$ & 1 & 0.10578 & 0.10578 & 0.10578 & 15.85 & 0.001 & $2.41 \%$ & Significant \\
\hline 2-way interaction & 3 & 0.07167 & 0.07167 & 0.02389 & 3.58 & 0.036 & $1.63 \%$ & \\
\hline$a^{*} V$ & 1 & 0.00013 & 0.00013 & 0.00013 & 0.02 & 0.889 & $0.00 \%$ & Not significant \\
\hline$a^{*} f$ & 1 & 0.06750 & 0.06750 & 0.06750 & 10.11 & 0.005 & $1.54 \%$ & Significant \\
\hline$V^{*} f$ & 1 & 0.00403 & 0.00403 & 0.00403 & 0.60 & 0.448 & $0.09 \%$ & Not significant \\
\hline Error & 17 & 0.11345 & 0.11345 & 0.00667 & & & $2.59 \%$ & \\
\hline Total & 26 & 4.38419 & & & & & $100.00 \%$ & \\
\hline
\end{tabular}

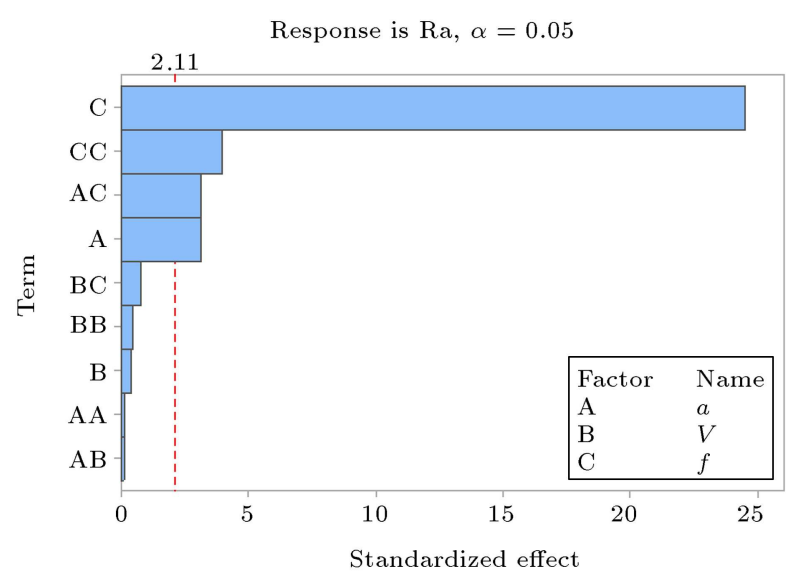

Figure 5. Pareto chart of standardized effects for surface roughness.

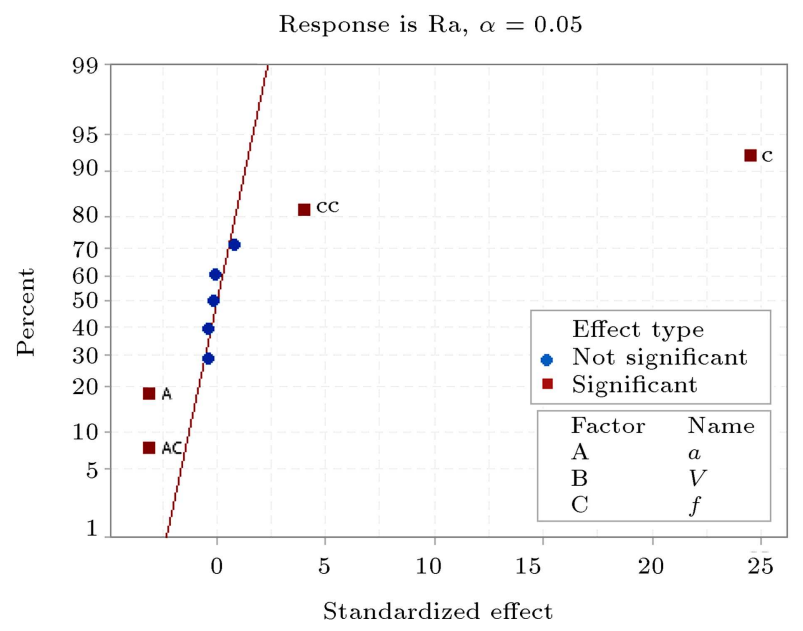

Figure 6. Normal plot of standardized effects for surface roughness. that have a positive effect on response variables are placed on the right side of the distribution fit line. The normal plot also shows that the surface roughness is mainly affected by the feed rate followed by $\left(f^{2}\right)$. It means that by increasing the feed rate, the surface roughness also increases. The $\left(a^{*} f\right)$ and $(a)$ have minimum negative effect on surface quality. It means that upon increasing the cutting depth, the surface roughness decreases.

The surface plots for surface roughness are provided in Figure 7 . The surface plot for the interaction of $(V-a)$ with surface roughness (hold value: $f=$ $0.1 \mathrm{~mm} / \mathrm{rev}$ ) shows that surface roughness slightly decreases by increasing the cutting depth, whereas the cutting speed almost exhibits no impact on surface quality. The surface plot for the interaction between feed rate-depth of cut $(f-a)$ and surface roughness (hold value: $V=200 \mathrm{~m} / \mathrm{min}$ ) shows that surface roughness is significantly affected by feed rate. The surface roughness increases upon increasing the feed rate. The depth of cut has a minor impact on surface quality. Finally, the surface plot for the interaction between feed rate-cutting speed $(f-V)$ and surface roughness (hold value: $a=0.1 \mathrm{~mm}$ ) indicates that cutting speed has no impact on surface quality; however, surface roughness sharply increases by increasing the feed rate.

\subsection{Power consumption (PW)}

Table 5 shows the results of the ANOVA for power consumption. It is of great importance for a company to reduce power consumption due to the high cost of electricity and also some environmental problems. Therefore, the influences of cutting parameters on the 


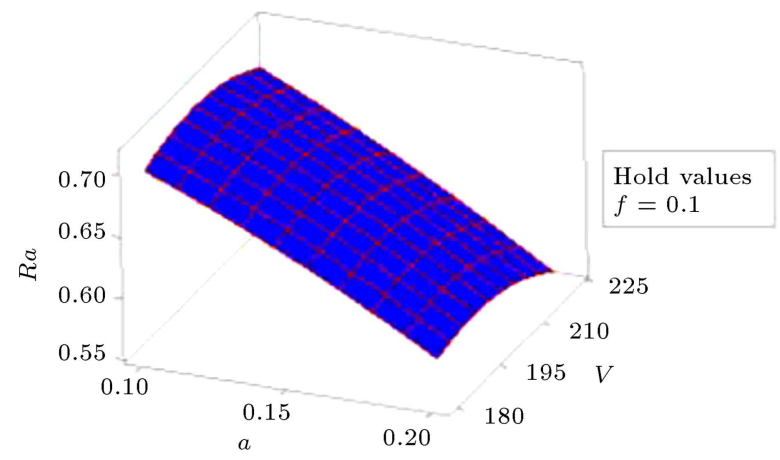

(a)

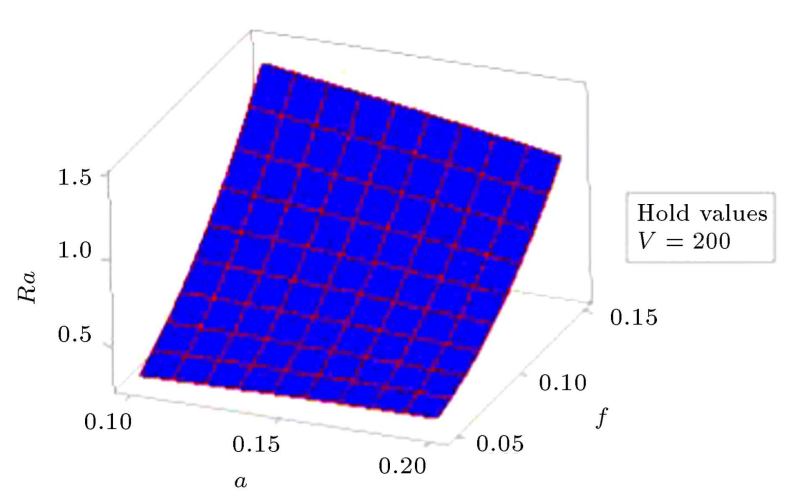

(b)

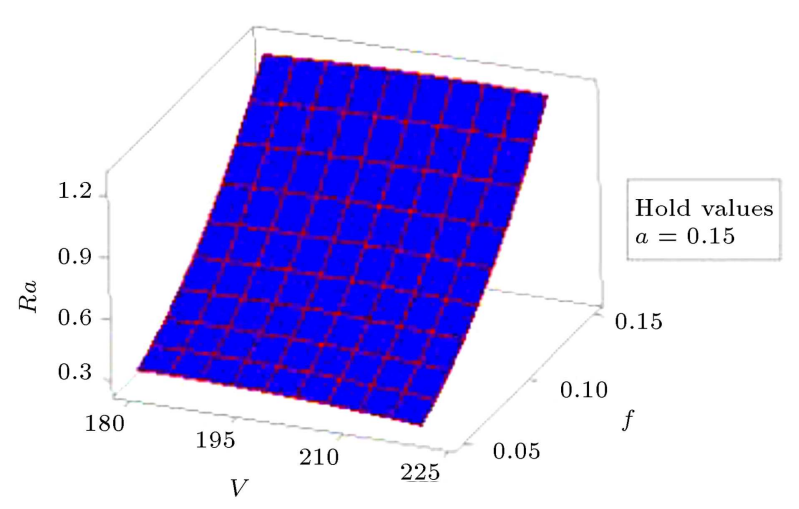

(c)

Figure 7. Surface plots for surface roughness: (a) $V-a$, (b) $f-a$, and (c) $f-V$.

power consumption are determined to determine the effective parameters in this study. According to the results, all three machining parameters, namely feed rate, cutting speed, and depth of cut, have a great impact on the power consumption by $43.61 \%, 30.71 \%$, and $19.78 \%$ contributions, respectively. Gaitonde et al. [30] and Aouici et al. [32] found the same result in their study that verified the influence of feed rate on power consumption as the dominant factor. Increasing each of cutting parameters results in an increase in cutting forces and consequently high power consumption. Furthermore, the interaction of $(f-a)$ with $(2.51 \%)$ and $(f-V)$ with $(1.39 \%)$ contribution has minor effect

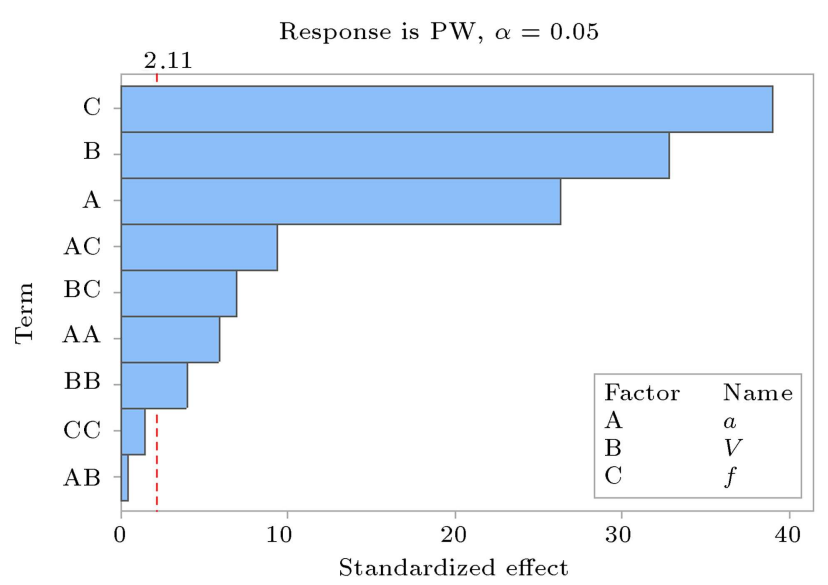

Figure 8. Pareto chart of standardized effects for power consumption.

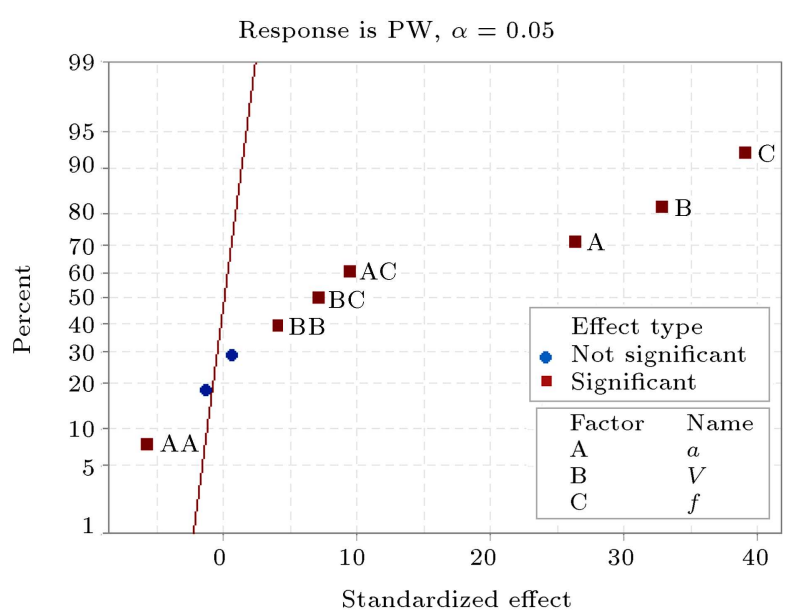

Figure 9. Normal plot of standardized effects for power consumption.

on power consumption. The $\left(a^{2}\right)$ and $\left(V^{2}\right)$ have a total contribution of $1.54 \%$ on power.

The Pareto chart and the normal plot of standardized effects for power consumption are presented in Figures 8 and 9 , respectively. The Pareto chart shows that power consumption is mainly affected by $(f),(V)$, and $(a)$, in order. The interaction of $\left(a^{*} f\right)$ and $\left(a^{*} V\right)$ as well as a square of cutting speed and depth of cut have also a minimum impact on response. The normal plot of the standardized effects shows the positive influence of all machining parameters on the power consumption except $\left(a^{2}\right)$. Thus, as the level of the cutting parameter enhances, the greater power is consumed.

The surface plots for power consumption are provided in Figure 10. In these plots, the hold value for $a-V$ is $(f=0.1 \mathrm{~mm} / \mathrm{rev})$, for $a-f$ is $(V=200$ $\mathrm{mm} / \mathrm{min})$, and for $V-f$ is $(a=0.15 \mathrm{~mm})$. The surface plot for the interaction of a-V with $\mathrm{PW}$ indicates that power consumption sharply increases upon increasing both the depth of cut and cutting speed. However, the cutting speed is dominant in comparison to the depth of cut. The surface plot for the interaction of $a-f$ with 
Table 5. The ANOVA results for power consumption.

\begin{tabular}{|c|c|c|c|c|c|c|c|c|}
\hline Source & DF & Seq SS & $\operatorname{Adj} \mathrm{SS}$ & Adj MS & $F$-value & $P$-value & Contribution & Remarks \\
\hline Model & 9 & 652406 & 652406 & 72490 & 387.62 & 0.000 & $99.52 \%$ & \\
\hline Linear & 3 & 616920 & 616920 & 205640 & 1099.61 & 0.000 & $94.10 \%$ & \\
\hline$a$ & 1 & 129642 & 129642 & 129642 & 693.23 & 0.000 & $19.78 \%$ & Significant \\
\hline$V$ & 1 & 201359 & 201359 & 201359 & 1076.71 & 0.000 & $30.71 \%$ & Significant \\
\hline$f$ & 1 & 285919 & 285919 & 285919 & 1528.88 & 0.000 & $43.61 \%$ & Significant \\
\hline Square & 3 & 9863 & 9863 & 3288 & 17.58 & 0.000 & $1.50 \%$ & \\
\hline$a^{2}$ & 1 & 6508 & 6508 & 6508 & 34.80 & 0.000 & $0.99 \%$ & Significant \\
\hline$V^{2}$ & 1 & 2948 & 2948 & 2948 & 15.76 & 0.001 & $0.45 \%$ & Significant \\
\hline$f^{2}$ & 1 & 407 & 407 & 407 & 2.17 & 0.159 & $0.06 \%$ & Not significant \\
\hline 2-way interaction & 3 & 25624 & 25624 & 8541 & 45.67 & 0.000 & $3.91 \%$ & \\
\hline$a^{*} V$ & 1 & 43 & 43 & 43 & 0.23 & 0.636 & $0.01 \%$ & Not significant \\
\hline$a^{*} f$ & 1 & 16472 & 16472 & 16472 & 88.08 & 0.000 & $2.51 \%$ & Significant \\
\hline$V^{*} f$ & 1 & 9108 & 9108 & 9108 & 48.70 & 0.000 & $1.39 \%$ & Significant \\
\hline Error & 17 & 3179 & 3179 & 187 & & & $0.48 \%$ & \\
\hline Total & 26 & 655586 & & & & & $100.00 \%$ & \\
\hline
\end{tabular}

Table 6. The ANOVA results for sound.

\begin{tabular}{|c|c|c|c|c|c|c|c|c|}
\hline Source & DF & Seq SS & $\operatorname{Adj} \mathrm{SS}$ & Adj MS & $F$-value & $P$-value & Contribution & Remarks \\
\hline Model & 9 & 8.85611 & 8.85611 & 0.98401 & 24.67 & 0.000 & $92.89 \%$ & \\
\hline Linear & 3 & 5.72722 & 5.72722 & 1.90907 & 47.87 & 0.000 & $60.07 \%$ & \\
\hline$a$ & 1 & 0.80222 & 0.80222 & 0.80222 & 20.12 & 0.000 & $8.41 \%$ & Significant \\
\hline$V$ & 1 & 4.20500 & 4.20500 & 4.20500 & 105.44 & 0.000 & $44.10 \%$ & Significant \\
\hline$f$ & 1 & 0.72000 & 0.72000 & 0.72000 & 18.05 & 0.001 & $7.55 \%$ & Significant \\
\hline Square & 3 & 2.85722 & 2.85722 & 0.95241 & 23.88 & 0.000 & $29.97 \%$ & \\
\hline$a^{2}$ & 1 & 1.85185 & 1.85185 & 1.85185 & 46.44 & 0.000 & $19.42 \%$ & Significant \\
\hline$V^{2}$ & 1 & 0.98685 & 0.98685 & 0.98685 & 24.75 & 0.000 & $10.35 \%$ & Significant \\
\hline$f^{2}$ & 1 & 0.01852 & 0.01852 & 0.01852 & 0.46 & 0.505 & $0.19 \%$ & Not significant \\
\hline 2-way interaction & 3 & 0.27167 & 0.27167 & 0.09056 & 2.27 & 0.117 & $2.85 \%$ & \\
\hline$a^{*} V$ & 1 & 0.18750 & 0.18750 & 0.18750 & 4.70 & 0.045 & $1.97 \%$ & Significant \\
\hline$a^{*} f$ & 1 & 0.00083 & 0.00083 & 0.00083 & 0.02 & 0.887 & $0.01 \%$ & Not significant \\
\hline$V^{*} f$ & 1 & 0.08333 & 0.08333 & 0.08333 & 2.09 & 0.166 & $0.87 \%$ & Not significant \\
\hline Error & 17 & 0.67796 & 0.67796 & 0.03988 & & & $7.11 \%$ & \\
\hline Total & 26 & 9.53407 & & & & & $100.00 \%$ & \\
\hline
\end{tabular}

PW indicates that power consumption is considerably affected by feed rate followed by the depth of cut. As the feed rate increases, the power consumption is also enhanced. Finally, the surface plot for the interaction of $V-f$ with power consumption exhibits the same effect as the $a-f$ plot.

\subsection{Sound (S)}

The results of the ANOVA for sound are presented in Table 6. Another way to investigate the machinability of the materials is detecting the sound fluctuations during the machining operation. In this study, cutting speed was a dominant factor that affected sound by $44.10 \%$. The squares of $(a)$ and $(V)$ are the next important parameters by $19.42 \%$ and $10.35 \%$, respectively. The other two machining parameters, namely depth of cut and feed rate, were also effective in sound by $8.41 \%$ and $7.55 \%$, respectively. Finally, the interaction of cutting depth and cutting speed has a minor impact on sound by $1.97 \%$.

The Pareto chart and the normal plot of standardized effects for sound are presented in Figures 11 and 12, respectively. The Pareto chart shows that the sound is significantly influenced by cutting speed. 


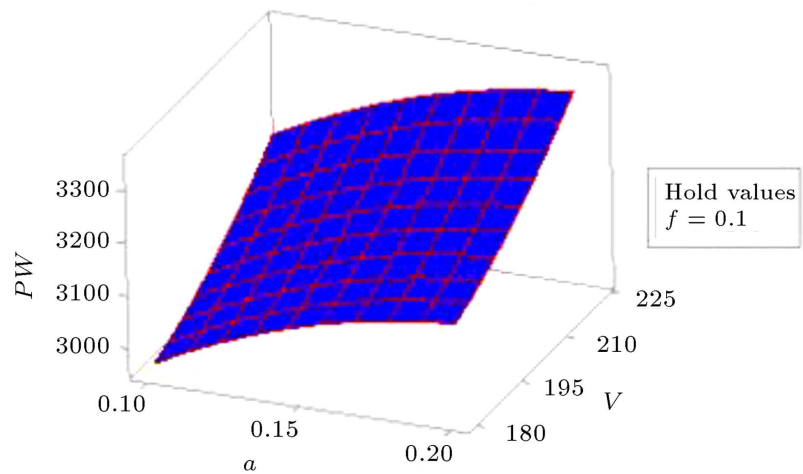

(a)

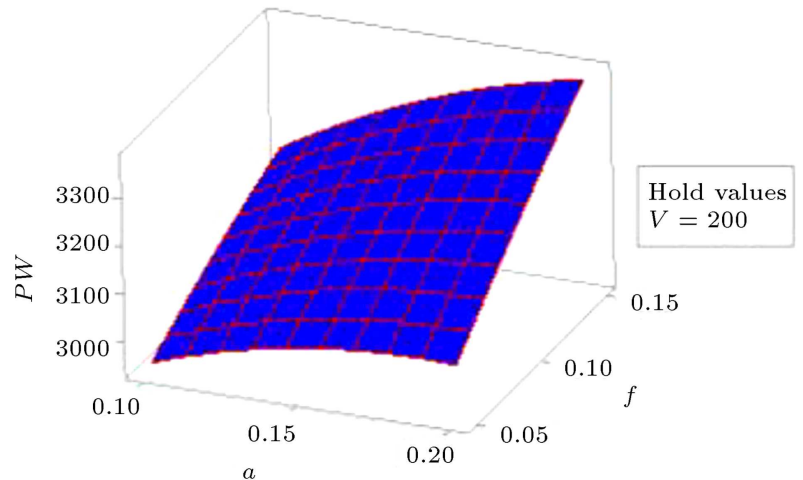

(b)

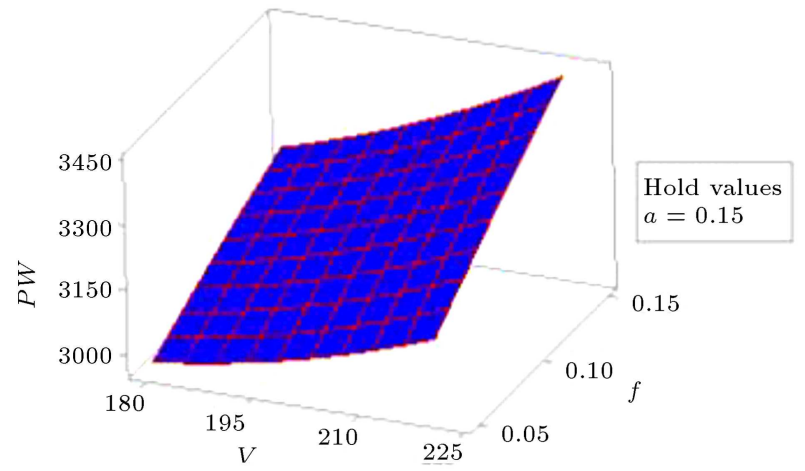

(c)

Figure 10. Surface plots for power consumption: (a) $V-a$, (b) $f-a$, and (c) $f-V$.

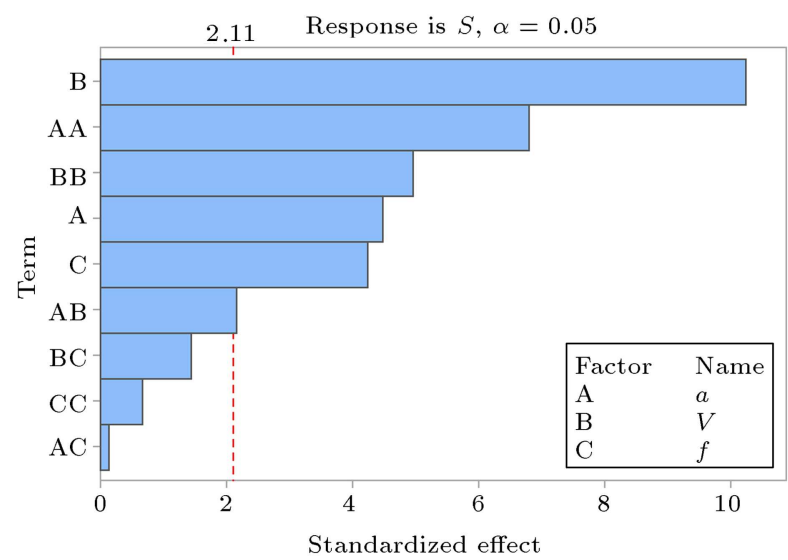

Figure 11. Pareto chart of standardized effects for sound.

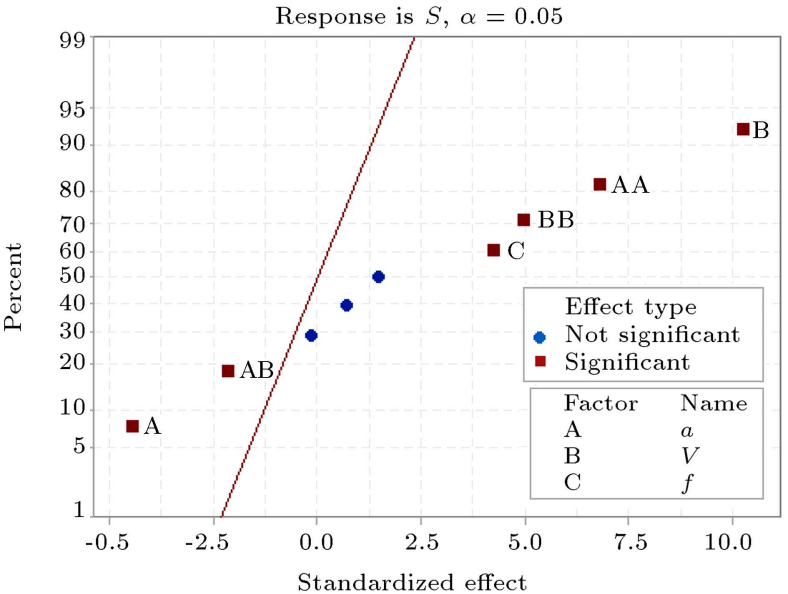

Figure 12. Normal plot of standardized effects for sound.

The squares of $(a)$ and $(V)$ are the next effective parameters in sound. The depth of cut and feed rate also affect the sound. According to the normal plot of standardized effects, the cutting speed has a positive impact on sound followed by $\left(a^{2}\right),\left(V^{2}\right)$, and feed rate. It means that as the aforementioned parameters increase in value, the value of sound factor also increases. However, the cutting depth and $\left(a^{*} V\right)$ have a negative influence on the sound; thus, as the cutting depth increases, the sound decreases.

The surface plots for sound are illustrated in Figure 13. The surface plot for the interaction of $(a-V)$ with the sound indicates that the sound sharply increases by increasing the cutting speed at $f=0.1 \mathrm{~mm} / \mathrm{rev}$ and $a=0.1 \mathrm{~mm}$. However, as the depth of cut increases from $0.1 \mathrm{~mm}$ to $0.15 \mathrm{~mm}$, the sound slightly decreases and increases afterwards. The same phenomenon happens in the surface plot in the case of the interaction of depth of cut and feed rate with sound. The sound decreases by increasing the depth of cut until $0.15 \mathrm{~mm}$ and, then, it increases. According to this plot, sound is enhanced as the feed rate increases. Finally, the surface plot for feed rate and cutting speed shows that the value for the sound factor increases sharply upon increasing the cutting speed and the feed rate. Increasing the feed rate at $V=220 \mathrm{~m} / \mathrm{min}$ and $a=0.15 \mathrm{~mm}$ enhances the sound.

\subsection{Regression equations}

The multiple regression analysis is utilized to determine the relationship between machining parameters and responses. The RSM-based second-order polynomial equations were developed for determining the values of surface roughness (Ra), power consumption (PW), and sound $(S)$ based on machining factors including feed rate $(f)$, cutting speed $(V)$, and depth of cut (a) during turning of hardened AISI S1 tool steel employing CBN cutting tools. The main formula for predicting responses according to cutting parameters 


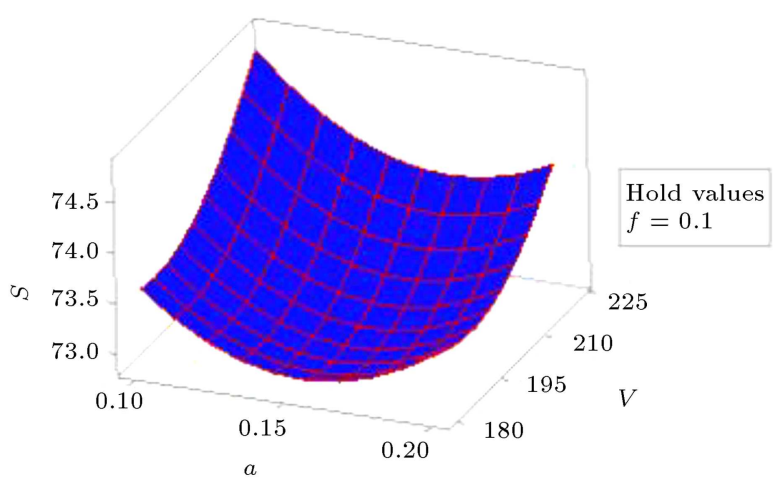

(a)

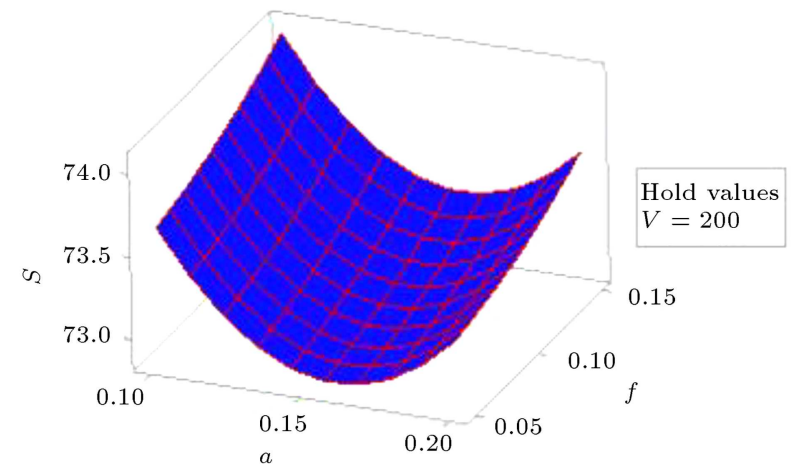

(b)

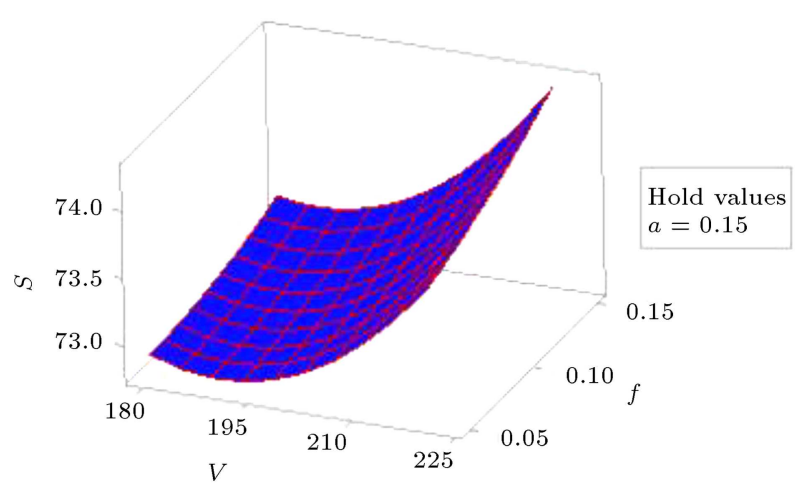

(c)

Figure 13. Surface plots for sound: (a) $V-a$, (b) $f-a$, and (c) $f-V$.

is given in Eq. (3):

$$
\begin{gathered}
Y=b_{0}+b_{1} a+b_{2} V+b_{3} f+b_{11} a^{2}+b_{22} V^{2}+b_{33} f^{2} \\
+b_{12} a * V+b_{13} a * f+b_{23} V * f
\end{gathered}
$$

where $Y$ is the desired output parameter and $b_{0}, b_{1}, \ldots, b_{33}$ are regression coefficients to be determined for each output parameter. The mathematical models for (Ra), (PW), and (S) are presented in Eqs. (4), (5), and $(6)$, respectively:

A mathematical model for surface roughness (Ra)

$$
\begin{aligned}
R a= & -1.285926+3.111111 a+0.013833 V \\
& -0.333333 f-2.222222 a^{2}-0.000039 V^{2} \\
& +53.111111 f^{2}-0.003333 a * V-30 a * f \\
& +0.183333 V * f \\
R^{2}= & 97.41 \%
\end{aligned}
$$

A Mathematical model for power consumption (PW)

$$
\begin{aligned}
P W= & 4317.01+3787.33 a-19.92 V-4553.66 f \\
& -13173.33 a^{2}+0.0554 V^{2}-3293.33 f^{2} \\
& +1.9 a * V+14820 a * f+27.55 V * f \\
R^{2}= & 99.52 \%
\end{aligned}
$$

A Mathematical model for sound (S)

$$
\begin{aligned}
S= & 112.081481-45.555556 a-0.370972 V \\
& -16.6111111 f+222.222222 a^{2}+0.001014 V^{2} \\
& +22.222222 f^{2}-0.125 a * V-3.333333 a * f \\
& +0.0833333 V * f \\
R^{2} & =92.89 \% .
\end{aligned}
$$

In addition, the coefficient of determination $\left(R^{2}\right)$ which is the ratio of the explained variation to the total variation is presented. The presented mathematical model is significant when the $R^{2}$ tends to be $100 \%$. In this case, the predicted data fits the actual data. The coefficient of determination for surface roughness is $97.41 \%$, which indicates the accuracy of the proposed model. The $R^{2}=99.52 \%$ shows that the proposed mathematical model can accurately predict power consumption. Finally, the $R^{2}$ of $92.89 \%$ indicates that the sound of the machining process can be predicted using the mathematical model.

\subsection{Optimization of output parameters}

In manufacturing processes, one of the most important goals is to minimize surface roughness and power consumption to determine the best surface quality and reduce the processing cost. RSM optimization is used to obtain the optimum machining parameters based on the output parameters.

In the hard turning of AISI S1 steel, response optimization is utilized to determine the optimum cutting parameters that minimize the surface roughness, power consumption, and sound. The desirability (d) value is used to measure the impact of each response and 
Table 7. Predicted results, absolute error (AE\%), and an average of absolute (AAE\%) error using Response Surface Methodology (RSM).

\begin{tabular}{|c|c|c|c|c|c|c|c|c|c|}
\hline \multirow[b]{2}{*}{ Trial no } & \multicolumn{3}{|c|}{$R a(\mu \mathrm{m})$} & \multicolumn{3}{|c|}{$P W$ (Watt) } & \multicolumn{3}{|c|}{$S(\mathrm{~dB})$} \\
\hline & Exp. & RSM & $\mathrm{AE}(\%)$ & Exp. & RSM & $\mathrm{AE}(\%)$ & Exp. & RSM & $\mathrm{AE}(\%)$ \\
\hline 1 & 0.29 & 0.30 & 3.40 & 2861.4 & 2873.7 & 0.41 & 73.4 & 73.5 & 0.13 \\
\hline 2 & 0.86 & 0.78 & 9.30 & 2975.4 & 2963.3 & 0.40 & 73.6 & 73.6 & 0 \\
\hline 3 & 1.26 & 1.35 & 7.14 & 3032.4 & 3016.5 & 0.52 & 73.7 & 73.7 & 0 \\
\hline 4 & 0.22 & 0.24 & 9.09 & 2964.0 & 2947.7 & 0.57 & 73.5 & 73.6 & 0.13 \\
\hline 5 & 0.76 & 0.70 & 7.89 & 3043.8 & 3044.9 & 0.03 & 73.8 & 73.8 & 0 \\
\hline 6 & 1.33 & 1.38 & 3.75 & 3123.6 & 3125.6 & 0.06 & 74.0 & 74.0 & 0 \\
\hline 7 & 0.25 & 0.25 & 0 & 3055.2 & 3046.1 & 0.29 & 74.8 & 74.6 & 0.26 \\
\hline 8 & 0.72 & 0.69 & 4.16 & 3169.2 & 3170.8 & 0.04 & 75.0 & 74.8 & 0.26 \\
\hline 9 & 1.42 & 1.39 & 2.11 & 3271.8 & 3279.1 & 0.21 & 75.2 & 75.2 & 0 \\
\hline 10 & 0.28 & 0.30 & 7.14 & 2986.8 & 2972.6 & 0.46 & 73.1 & 72.9 & 0.27 \\
\hline 11 & 0.67 & 0.65 & 2.98 & 3078.0 & 3079.2 & 0.03 & 73.2 & 73.0 & 0.27 \\
\hline 12 & 1.20 & 1.23 & 2.50 & 3157.8 & 3169.5 & 0.38 & 73.3 & 73.2 & 0.13 \\
\hline 13 & 0.30 & 0.31 & 3.33 & 3032.4 & 3028.4 & 0.13 & 73.1 & 72.9 & 0.27 \\
\hline 14 & 0.72 & 0.66 & 8.33 & 3169.2 & 3162.7 & 0.22 & 73.0 & 73.0 & 0 \\
\hline 15 & 1.35 & 1.26 & 6.66 & 3283.2 & 3280.5 & 0.09 & 73.2 & 73.3 & 0.13 \\
\hline 16 & 0.29 & 0.27 & 6.89 & 3123.6 & 3128.6 & 0.16 & 73.3 & 73.5 & 0.27 \\
\hline 17 & 0.57 & 0.62 & 8.77 & 3294.6 & 3290.5 & 0.12 & 73.6 & 73.8 & 0.27 \\
\hline 18 & 1.23 & 1.25 & 1.62 & 3431.4 & 3435.8 & 0.11 & 74.3 & 74.3 & 0 \\
\hline 19 & 0.39 & 0.36 & 7.69 & 2998.2 & 2985.5 & 0.43 & 73.2 & 73.3 & 0.13 \\
\hline 20 & 0.51 & 0.55 & 7.84 & 3135.0 & 3129.3 & 0.19 & 73.3 & 73.4 & 0.13 \\
\hline 21 & 1.14 & 1.10 & 3.50 & 3249.0 & 3256.6 & 0.21 & 73.5 & 73.6 & 0.13 \\
\hline 22 & 0.31 & 0.32 & 3.22 & 3032.4 & 3043.3 & 0.36 & 73.3 & 73.3 & 0 \\
\hline 23 & 0.52 & 0.56 & 7.69 & 3203.4 & 3214.6 & 0.34 & 73.4 & 73.4 & 0 \\
\hline 24 & 1.16 & 1.12 & 3.44 & 3374.4 & 3369.5 & 0.14 & 73.7 & 73.6 & 0.13 \\
\hline 25 & 0.39 & 0.36 & 7.69 & 3146.4 & 3145.4 & 0.03 & 74.1 & 74.0 & 0.13 \\
\hline 26 & 0.45 & 0.49 & 8.88 & 3340.2 & 3344.3 & 0.11 & 74.2 & 74.2 & 0 \\
\hline 27 & 1.14 & 1.11 & 2.63 & 3545.4 & 3536.7 & 0.25 & 74.5 & 74.5 & 0 \\
\hline $\operatorname{AAE}(\%)$ & & & 5.46 & & & 0.23 & & & 0.11 \\
\hline
\end{tabular}

the composite desirability is a considerable criterion for all responses. Composite desirability is the arithmetic mean of each response desirability and it ranges from zero to one. If the composite desirability value tends to zero, the responses are not optimized well, whereas if it tends to one, the optimized value for responses is obtained. Figure 14 shows the optimization plot for the responses. According to this figure, the optimum cutting parameters for the minimum responses are obtained as $a(0.13 \mathrm{~mm}), V(180.4 \mathrm{~m} / \mathrm{min})$, and $f$ $(0.05 \mathrm{~mm} / \mathrm{rev})$. In addition, the optimized response for surface roughness is $0.319 \mu \mathrm{m}$ with $d=0.917$, for power consumption 2952 Watt with $d=0.867$, and for sound $72.999 \mathrm{~dB}$ with $d=1$. Finally, the composite desirability for this study is obtained as 0.926 .

\subsection{Confirmation test}

The confirmation test was carried out on all sets of input factors to verify the validity of the proposed mathematical models. The experimental results, the predicted results, the Absolute Error (AE\%), and the Average of Absolute Errors (AE\%) for the responses are presented in Table 7 . The AE\% for each test is calculated using Eq. (7):

$$
A E(\%)=\left[\frac{\mid \text { experimental }- \text { predicted } \mid}{\text { experimental }}\right] * 100
$$

According to the result, the AAE values for sound, power consumption, and surface roughness are $0.11 \%$, $0.23 \%, 5.46 \%$, respectively. These results show that the presented model can predict the response with very good accuracy.

In addition, the comparison between experimental and predicted values for responses, namely surface roughness, power consumption, and sound, is illustrated in Figures 15, 16, and 17, respectively. These graphs show good agreement between experimental and predicted values for output parameters. 


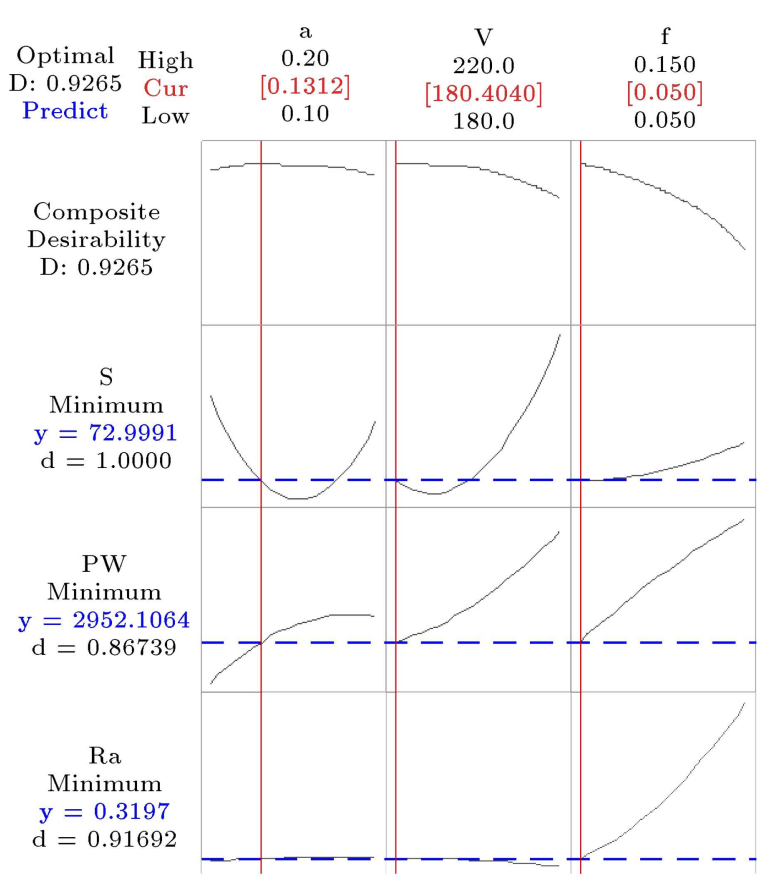

Figure 14. Response optimization plot for sound $(S)$, power consumption $(P W)$, and surface roughness $(R a)$.

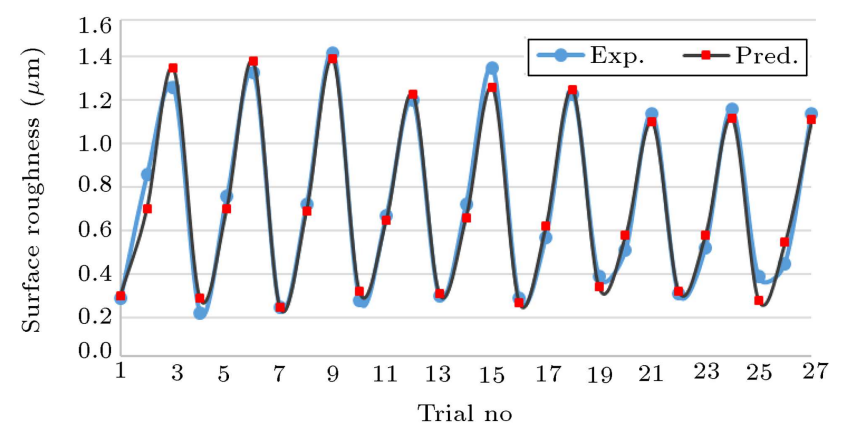

Figure 15. Comparison between experimental and predicted values of surface roughness.

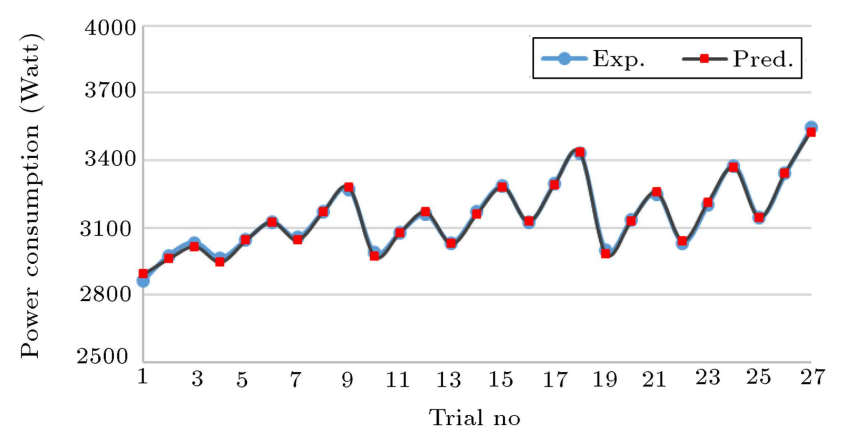

Figure 16. Comparison between experimental and predicted values of power consumption.

\section{Conclusion}

In the presented work, the hard turning was applied to AISI S1 cold work tool steel using cubic boron nitride inserts to investigate the machinability factors such as surface roughness, power consumption, and

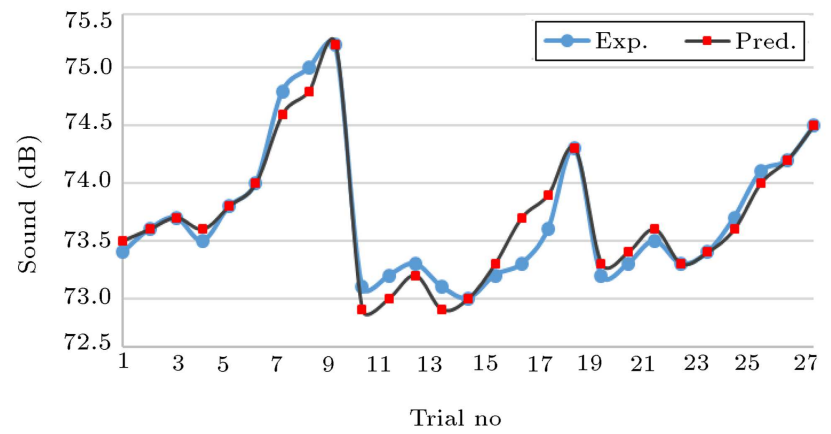

Figure 17. Comparison between experimental and predicted values of sound.

sound. The cutting speed, depth of cut, and feed rate were chosen as machining parameters, and Response Surface Methodology (RSM) was employed to create an experimental design. The Analysis Of Variance (ANOVA) was used to detect the most important factors that would influence the responses. Finally, the mathematical models were proposed for each output parameter and the confirmation test was performed to compare the results of experimental and predicted values. The outcomes of this study are listed below.

Based on the ANOVA results, feed rate had a major effect on surface roughness by $91.77 \%$. The product of feed rate and interaction of $\left(a^{*} f\right)$ had a minor impact on the ( $\mathrm{Ra}$ ) by $2.41 \%$ and $1.54 \%$, respectively. According to the surface plots, surface roughness had a direct relation with the feed rate. The surface quality deteriorated as the feed rate increased. According to the metal cutting theory, the feed rate was the most significant parameter that affected surface roughness. The feed rate had a direct relation with surface roughness, while nose radius had an indirect relationship with it. Thus, as the feed rate increased, the cutting forces increased; hence, vibration was created which would result in chatter on the machined surface that adversely affects the surface quality and deteriorates the surface of the workpiece. According to workpiece material, the hardness of the workpiece, cutting tools type, machining parameters, and other criteria cutting speed could also have a significant effect on the surface quality. However, in this study, the depth of cut and cutting speed did not exhibit any considerable effect on the surface quality. In some cases, the combination of low feed rate value and high cutting speed should be selected to minimize the surface roughness. Also, the normal plot and the Pareto chart of standardized effects exhibited the same results for surface roughness. The surface roughness was modeled with a $97.41 \%$ coefficient of determination. Therefore, the experimental results and the predicted results through a mathematical equation were so close to each other.

Determining the optimum cutting parameters for 
minimizing the power consumption and consequently reducing the cost of manufacturing is inevitable. In this study, the results of the ANOVA for power consumption show that feed rate is the most important parameter by $43.61 \%$. Following the feed rate, cutting speed and depth of cut had also significant contributions of $30.71 \%$ and $19.78 \%$. The other factors such as machining parameters 2-way interaction and squares contributed to the power consumption by $3.91 \%$ and $1.50 \%$, respectively. The normal plot of standardized effect shows that all machining parameters have a positive impact on power consumption. Based on the surface plots, by increasing the values of feed rate, cutting speed, and depth of cut, the power consumption sharply increases. The $R^{2}$ for power consumption was $99.52 \%$ and the comparison between the predicted values from the mathematical model and experimental values exhibited almost identical results for both.

Optimization of cutting parameters based on sound is another method to determine the machinability of the workpiece. The ANOVA results showed that cutting speed was a significant factor that affected sound by $44.10 \%$. The $\left(a^{2}\right)$ and $\left(V^{2}\right)$ had a great impact on the sound by $19.42 \%$ and $10.35 \%$, respectively. The cutting depth and feed rate contributed by $8.41 \%$ and $7.55 \%$ to the sound, respectively. The Pareto chart and the normal plot of standardized effects for sound are presented in Figures 11 and 12, respectively. The Pareto chart shows that the sound was significantly influenced by cutting speed. The squares of the cutting depth and cutting speed were the next effective parameters in sound. The depth of cut and feed rate also affected the sound. According to the normal plot of standardized effects, the cutting speed had a positive impact on sound followed by $\left(a^{2}\right),\left(V^{2}\right)$, and feed rate. It means that if the aforesaid parameters increased in value, the response (sound) would also increase. The surface plots for sound illustrated that increasing the cutting speed and feed rate increased the sound. However, increasing the depth of cut from 0.10 $\mathrm{mm}$ to $0.15 \mathrm{~mm}$ decreased the sound. The coefficient of determination $\left(R^{2}=92.89 \%\right)$ indicated good agreement between experimental and predicted results.

\section{References}

1. Tönshoff, H., Arendt, C., and Amor, R.B. "Cutting of hardened steel", Cirp Annals, 49(2), pp. 547-566 (2000).

2. Mia, M. and Dhar, N.R. "Prediction of surface roughness in hard turning under high pressure coolant using artificial neural network", Measurement, 92, pp. 464474 (2016).

3. Yıldırım, Ç.V. "Investigation of hard turning performance of eco-friendly cooling strategies: Cryogenic cooling and nanofluid based MQL", Tribology International, 144, p. 106127 (2020).

4. Klocke, F., Brinksmeier, E., and Weinert, K. "Capability profile of hard cutting and grinding processes", CIRP Annals, 54(2), pp. 22-45 (2005).

5. Bartarya, G. and Choudhury, S. "State of the art in hard turning", International Journal of Machine Tools and Manufacture, 53(1), pp. 1-14 (2012).

6. Poulachon, G., Bandyopadhyay, B., Jawahir, I., Pheulpin, S., and Seguin, E. "Wear behavior of CBN tools while turning various hardened steels", Wear, 256(3-4), pp. 302-310 (2004).

7. Özel, T. and Karpat, Y. "Predictive modeling of surface roughness and tool wear in hard turning using regression and neural networks", International Journal of Machine Tools and Manufacture, 45(4), pp. 467-479 (2005).

8. More, A.S., Jiang, W., Brown, W., and Malshe, A.P. "Tool wear and machining performance of CBN-TiN coated carbide inserts and PCBN compact inserts in turning AISI 4340 hardened steel", Journal of Materials Processing Technology, 180(1-3), pp. 253262 (2006).

9. Kumar, P., Chauhan, S.R., Pruncu, C.I., Gupta, M.K., Pimenov, D.Y., Mia, M., and Gill, H.S. "Influence of different grades of $\mathrm{CBN}$ inserts on cutting force and surface roughness of AISI H13 die tool steel during hard turning operation", Materials, 12(1), p. 177 (2019).

10. Tamizharasan, T., Selvaraj, T., and Haq, A.N. "Analysis of tool wear and surface finish in hard turning", The International Journal of Advanced Manufacturing Technology, 28(7-8), pp. 671-679 (2006).

11. Khan, S.A., Anwar, S., Ishfaq, K., Afzal, M.Z., Ahmad, S., and Saleh, M. "Wear performance of modified inserts in hard turning of AISI D2 steel: A concept of one-step sustainable machining", Journal of Manufacturing Processes, 60, pp. 457-469 (2020).

12. Bagaber, S.A. and Yusoff, A.R. "Multi-responses optimization in dry turning of a stainless steel as a key factor in minimum energy", The International Journal of Advanced Manufacturing Technology, 96(1-4), pp. 1109-1122 (2018).

13. Salimi Asl, A., Erdem, A., and Rafighi, M. "Applying a multi sensor system to predict and simulate the tool wear using of artificial neural networks", Scientia Iranica, 24(6), pp. 2864-2874 (2017).

14. Mia, M., Dey, P.R., Hossain, M.S., Arafat, M.T., Asaduzzaman, M., Ullah, M.S., and Zobaer, S.T. "Taguchi S/N based optimization of machining parameters for surface roughness, tool wear and material removal rate in hard turning under MQL cutting condition", Measurement, 122, pp. 380-391 (2018). 
15. Muhammad, R., Ahmed, N., Maqsood, S., Alam, K., Ur Rehman, M., and Silberschmidt, V. "Influence of tool material on forces, temperature, and surface quality of Ti-15333 alloy in CT and UAT", Scientia Iranica, 26(5), pp. 2805-2816 (2019).

16. ÖZDEMiR, M., Kaya, M.T., and Akyildiz, H.K. "Analysis of surface roughness and cutting forces in hard turning of $42 \mathrm{CrMo} 4$ steel using Taguchi and RSM method", Mechanics, 26(3), pp. 231-241 (2020).

17. Özdemir, M. "Optimization with Taguchi method of influences on surface roughness of cutting parameters in CNC turning processing", Mechanics, 25(5), pp. 397-405 (2019).

18. Mia, M. and Dhar, N.R. "Modeling of surface roughness using RSM, FL and SA in dry hard turning", Arabian Journal for Science and Engineering, 43(3), pp. 1125-1136 (2018).

19. Kaçal, A. and Yıldırım, F. "High speed hard turning of AISI S1 (60WCrV8) cold work tool steel", Acta Polytechnica Hungarica, 10(8), pp. 169-186 (2013).

20. Aouici, H., Bouchelaghem, H., Yallese, M., Elbah, M., and Fnides, B. "Machinability investigation in hard turning of AISI D3 cold work steel with ceramic tool using response surface methodology", The International Journal of Advanced Manufacturing Technology, 73(9), pp. 1775-1788 (2014).

21. Tang, L., Sun, Y., Li, B., Shen, J., and Meng, G. "Wear performance and mechanisms of PCBN tool in dry hard turning of AISI D2 hardened steel", Tribology International, 132, pp. 228-236 (2019).

22. Tanvir, A.N.M., Ahsan, M.R., Seo, G., Bates, B., Lee, C., Liaw, P.K., Noakes, M., Nycz, A., Ji, C., and Kim, D.B. "Phase stability and mechanical properties of wire+ arc additively manufactured $\mathrm{H} 13$ tool steel at elevated temperatures", Journal of Materials Science \& Technology, 67, pp. 80-94 (2020).

23. Tanabi, H. and Rafighi, M. "Turning machinability of alloyed ductile iron compared to forged $\mathrm{EN}$ 1.7131 steel", Materials Testing, 62(12), pp. 1259-1264 (2020).

24. Gaitonde, V., Karnik, S., Figueira, L., and Davim, J.P. "Analysis of machinability during hard turning of cold work tool steel (type: AISI D2)", Materials and Manufacturing Processes, 24(12), pp. 1373-1382 (2009).

25. Chou, Y.K., Evans, C.J., and Barash, M.M. "Experimental investigation on CBN turning of hardened AISI 52100 steel", Journal of Materials Processing Technology, 124(3), pp. 274-283 (2002).

26. Davim, J.P. and Figueira, L. "Machinability evaluation in hard turning of cold work tool steel (D2) with ceramic tools using statistical techniques", Materials \& Design, 28(4), pp. 1186-1191 (2007).

27. Isik, Y. "Investigating the machinability of tool steels in turning operations", Materials \& Design, 28(5), pp. 1417-1424 (2007).
28. Bouacha, K., Yallese, M.A., Mabrouki, T., and Rigal, J.-F. "Statistical analysis of surface roughness and cutting forces using response surface methodology in hard turning of AISI 52100 bearing steel with CBN tool", International Journal of Refractory Metals and Hard Materials, 28(3), pp. 349-361 (2010).

29. Lima, J., Avila, R., Abrao, A., Faustino, M., and Davim, J.P. "Hard turning: AISI 4340 high strength low alloy steel and AISI D2 cold work tool steel", Journal of Materials Processing Technology, 169(3), pp. 388-395 (2005).

30. Gaitonde, V., Karnik, S., Figueira, L., and Davim, J.P. "Machinability investigations in hard turning of AISI D2 cold work tool steel with conventional and wiper ceramic inserts", International Journal of Refractory Metals and Hard Materials, 27(4), pp. 754-763 (2009).

31. Bensouilah, H., Aouici, H., Meddour, I., Yallese, M.A., Mabrouki, T., and Girardin, F. "Performance of coated and uncoated mixed ceramic tools in hard turning process", Measurement, 82, pp. 1-18 (2016).

32. Aouici, H., Bouchelaghem, H., Yallese, M., Elbah, M., and Fnides, B. "Machinability investigation in hard turning of AISI D3 cold work steel with ceramic tool using response surface methodology", The International Journal of Advanced Manufacturing Technology, 73(9-12), pp. 1775-1788 (2014).

33. Şahinoğlu, A. and Rafighi, M. "Investigation of vibration, sound intensity, machine current and surface roughness values of AISI 4140 during machining on the lathe", Arabian Journal for Science and Engineering, 45(2), pp. 765-778 (2020).

34. Şahinoğlu, A. and Rafighi, M. "Optimization of cutting parameters with respect to roughness for machining of hardened AISI 1040 steel", Materials Testing, 62(1), pp. 85-95 (2020).

\section{Biographies}

Abidin Şahinoğlu was born in Malatya (Turkey) in 1981. He completed his undergraduate and graduate education at Gazi University in Manufacturing Engineering. He works in the field of machine manufacturing and design. He has three patents in machine design and manufacturing. One of them is the "intelligent tool machining design" which determines the cutting parameters according to the sound and vibration analysis. He has published some papers related to the machining operation. He has worked at Çankırı Karatekin University, Department of Mechanical and Metal Technology as an instructor from 2012-2020. Since 2020, he has been working at Manisa Celal Bayar University, Department of Mechanical and Metal Technology as an Assistant Professor.

Mohammad Rafighi was born in Tabriz (Iran) in 1988. He received his BSc degree in Mechanical Engineering from the Islamic Azad University of Tabriz 
in 2010. He received his $\mathrm{MSc}$ and $\mathrm{PhD}$ degrees in Manufacturing Engineering from Gazi University in 2013 and 2018, respectively. Dr. Rafighi attended as a researcher to the Rolls-Royce Jet Engine Design Project at the Brandenburg University of Technology,
Cottbus, Germany. He has published some papers related to the machinability of steel. Since 2018, he has been working as an Assistant Professor at the University of Turkish Aeronautical Association, Department of Mechanical Engineering. 